\title{
TEKNOLOGI PENGOLAHAN TORAKUR (TOMAT RASA KURMA) SEBAGAI ALTERNATIF MENINGKATKAN NILAI EKONOMIS BUAH TOMAT DI DUSUN KAJANG KECAMATAN JUNREJO KOTA BATU
}

\author{
Technology Processing of Torakur (Tomato Taste Korma)) As Economical Alternative to \\ Increase the Value of Tomato Fruit at Dusun Kajang Junrejo Distric Batu City \\ Ernawati $^{1)}$, Hapsari Titi Palupi ${ }^{1)}$, Muhammad Nizar ${ }^{2)}$ \\ Fakultas Pertanian, Universitas Yudharta Pasuruan ${ }^{1)}$ \\ Fakultas Ekonomi Syariah, Universitas Yudharta Pasuruan ${ }^{2)}$ \\ email : ernawati.hariyadi@yahoo.com
}

\begin{abstract}
Dusun Kajang located in the Mojorejo village Kecamatan Junrejo Mojorejo Batu already has potential in agriculture. Tomato plants have grown very fertile, when the harvest season was very abundant. This causes, the price of tomatoes dropped dramatically, and easily damaged. Tomato (Solanum lycopersicum) is a vegetable that contains many nutrients as a source of vitamin $A, C, K$, folate potassium, thiamin, niacin, vitamin B6, so it is beneficial for health. Of these problems are given alternative that processing tomatoes into torakur (tomato flavor of korma) and processed tomatoes. The method of implementation are to synergize activities in the village program; extension of the tomatoes with training and diversification processing processed tomato products; training and guidance regarding sanitation and hygiene products; training production management, marketing and finance; as well as the continual to mentoring program of production process. The results of the program are to increase the capability and knowledge of both (farmer groups and the PKK) about tomatoes and processing of torakur and tomatoes products; improvement of skill processing torakur and processed tomatoes; able to utilize the tools of appropriate technology; increase the ability of mitra on a clean and hygienic production, business management and marketing of products.
\end{abstract}

Keywords: tomato, torakur, technology, processing

\begin{abstract}
ABSTRAK
Dusun Kajang terletak di Desa Mojorejo Kecamatan Junrejo Kota Batu memiliki potensi di bidang pertanian. Tanaman tomat tumbuh subur, bila musim panen maka tomat berlimpah. harga tomat menjadi menurun drastis, dan mudah mengalami kerusakan. Tomat (Solanum lycopersicum) merupakan sayuran yang banyak mengandung nutrisi yaitu sumber vitamin A,C, $\mathrm{K}$, kalium folat, thiamin, niasin, vitamin B6, sehingga sangat bermanfaat bagi kesehatan tubuh. Dari permasalahan tersebut diberikan alternatif olahan tomat menjadi torakur (tomat rasa kurma) dan beberapa produk olahan tomat. Metode pelaksanaan adalah mensinergikan kegiatan-kegiatan dalam program desa; penyuluhan tentang tomat disertai pelatihan proses pengolahan dan diversifikasi produk olahan tomat; pelatihan dan bimbingan mengenai sanitasi dan higienis produk; pelatihan manajemen produksi, pemasaran dan keuangan; serta pendampingan yang berkelanjutan untuk mengajak kelompok mitra melaksanakan proses produksi. Hasil pelaksanaan program adalah peningkatan kemampuan dan pengetahuan kedua Mitra yang berasal dari kelompok tani dan Kelompok PKK mengenai tomat, pengolahan tomat menjadi torakur dan olahan tomat; peningkatan ketrampilan proses pengolahan torakur dan olahan tomat; mampu memanfaatkan alih alat teknologi tepat guna; peningkatan kemampuan mitra tentang produksi bersih dan higienis, manajemen usaha dan pemasaran produk.
\end{abstract}

Kata kunci : tomat, torakur, teknologi, pengolahan 


\section{PENDAHULUAN}

Dusun Kajang terletak di wilayah Kecamatan Junrejo Kota Batu yang memiliki potensi di bidang pertanian, karena tanahnya subur dan sumber airnya cukup melimpah. Wilayah dusun Kajang tidak terlalu luas yaitu $\pm 95 \mathrm{Ha}$ dengan jumlah penduduk 2.840 jiwa terdiri dari 1.020 lakilaki dan 1.820 perempuan. Sebagian besar penduduk hidup dari bertani, menanam hasil pertanian di lahan milik sendiri atau menjadi buruh tani di lahan orang lain. Sumber air didapat dari sungai, mata air alami, air swadaya, dan PDAM. Air swadaya didapat dari sumber mata air alami yang dimanfaatkan dengan cara dialirkan ke rumah-rumah penduduk melalui paralon atau pipa yang pendanaannya dilakukan secara swadaya.

Seperti daerah di Kota Batu pada umumnya, lahan petani di dusun Kajang banyak ditanami berbagai sayuran dan palawija seperti sawi, tomat, kangkung, bawang merah, kol, padi dan lain-lain. Tomat (Solanum lycopersicum) merupakan salah satu tanaman yang banyak mengandung nutrisi sebagai sumber vitamin A,C, K, kalium folat, thiamin, niasin, vitamin B6, sehingga sangat bermanfaat bagi kesehatan tubuh. Menurut Kusmayadi (2014) tomat banyak mengandung vitamin dan mineral. Dalam sebuah tomat terdapat 30 kalori, vitamin C $40 \mathrm{mg}$, vitamin A 1500 SI, zat besi, kalsium dan lain lain. Karena mengandung zat tersebut, maka tomat juga berguna bagi orang-orang yang ingin langsing.

Tomat dapat tumbuh dengan subur di daerah ini dan bila musim panen tomat berlimpah, maka harga tomat dapat menurun drastis, sehingga merugikan petani tomat. Ditinjau dari aspek sosial budaya masyarakat dusun Kajang, ada kebiasaan jika harga tomat sudah terlalu anjlok, petani tidak jadi memanen tomat karena ongkos membayar upah buruh petik lebih mahal dibandingkan harga jualnya. Jika kondisi seperti itu, maka tomat yang sudah siap panen banyak yang jatuh di tanah atau membusuk begitu saja di pohonnya dan menjadi mubazir. Kondisi demikian tentu sangat memprihatinkan mengingat tomat merupakan bahan pangan yang begitu banyak manfaatnya.

Buah tomat mudah mengalami kerusakan jika tidak disimpan dengan baik dan salah satu alternatif yang dapat dilakukan dengan cara mengolahnya menjadi berbagai produk olahan antara lain sirup tomat, saos tomat, sambal tomat, manisan tomat, dan lain lain (Anonymous, 2014). Jika panen raya dan hasil panen melimpah, maka harga bisa turun secara drastis. Sedangkan bila diolah, maka nilai jual hasil olahan akan meningkat dan masyarakat setempat akan mendapatkan penghasilan tambahan. Hal ini akan meningkatkan taraf hidup masyarakat.

Torakur (tomat rasa kurma) adalah produk olahan unik berbahan dasar tomat yang rasanya sangat mirip dengan kurma. Produk ini dapat diolah dengan sentuhan teknologi yang sederhana dan tentunya memiliki harga jual yang lebih tinggi dibandingkan dijual dalam bentuk segar (belum diolah) yang harganya naik turun sesuai dengan keinginan pasar. Hal ini terjadi karena ketidak pahaman masayarakat setempat tentang jenis produk lain yang dapat dihasilkan dari bahan baku tomat, selain itu masyarakat juga belum memahami teknologi apa yang dapat diaplikasikan pada tomat yang mereka miliki.

Dari hasil analisis situasi yang diuraikan diatas dan hasil kesepakatan dengan kedua kelompok mitra ada beberapa permasalahan yang difokuskan dalam program ini adalah 1). kualitas sumber daya manusia yang perlu ditingkatkan, 2). pengetahuan dan kreativitas usaha yang masih kurang, 3). pemanfaatan hasil panen tomat belum maksimal, 4). kegiatan kelompok tani dan PKK yang belum optimal dan 5). peningkatan pengetahuan tentang sanitasi dan higienis yang kurang 6). pengetahuan pengemasan, manajemen usaha dan pemasaran lemah

Tujuan pengabdian adalah 1) Membentuk dan mengembangkan kelompok usaha yang mampu bersaing dalam era 
globalisasi; 2) Menerapkan teknologi pengolahan pangan tepat guna yang dapat membantu memecahkan masalah penurunan drastis harga tomat dan meningkatkan pendapatan masyarakat; 3) Meningkatkan pengetahuan dan kemampuan kelompok usaha tentang manajemen produksi, manajemen sumberdaya manusia dan manajemen pemasaran; 4) Membantu meningkatkan kreatifitas dan perekonomian kelompok usaha dan masyarakat dalam diversifikasi olahan pangan.

\section{METODE PELAKSANAAN}

\section{Bahan}

Bahan untuk pembuatan torakur dan produk olahan tomat (sari buah, permen jelly) adalah tomat, gula, asam sitrat, $\mathrm{CaCO}_{3}$, air, gelatin, karagenan, gula halus, $\mathrm{Na}$ benzoat, agar-agar, pengemas, gelas plastik, toples.

\section{Alat}

Alat-alat yang digunakan terdiri dari: pisau, talenan, baskom, timbangan, loyang, panci stainles steel, blender, piring, sendok, kompor, pengering, vacuum sealer, cup sealer.

\section{Metode}

Metode pelaksanaan adalah mensinergikan kegiatan-kegiatan dalam program desa; penyuluhan tentang tomat disertai pelatihan proses pengolahan torakur dan diversifikasi produk olahan tomat; pelatihan dan bimbingan mengenai sanitasi dan higienis produk; pelatihan manajemen produksi, pemasaran dan keuangan; serta pendampingan yang berkelanjutan untuk mengajak kelompok mitra melaksanakan proses produksi.

Selain itu dilakukan pengumpulan data sesudah kegiatan, dengan penyebaran kuisioner. Pengisian kuisioner bertujuan untuk mendapatkan data dari mitra setelah beberapa pelaksanaan program oleh Tim IbM. Data tersebut menilai tingkat pemahaman dan keterampilan mitra setealah program pelatihan oleh tim IBM dan sejauh mana minat mitra terhadap pengembangan usaha.

\section{HASIL DAN PEMBAHASAN}

\section{Pendekatan pada pemerintah desa setempat dan mitra}

Pendekatan dengan pemerintah desa Mojorejo Kecamatan Junrejo Kota Batu dilakukan untuk mensinergikan kegiatankegiatan dalam program pemerintah desa khususnya yang berkaitan dengan permasalahan untuk meningkatkan nilai ekonomis dari tomat pada waktu musim panen melimpah sehingga harga jualnya rendah. Dari hasil pendekatan tersebut ternyata sangat bermanfaat dan memudahkan tim mensosialisasikan program ke masyarakat, menambah tali silaturahmi dan memperluas jaringan hubungan.

\section{Pelaksanaan program}

\section{Penyuluhan tentang manfaat tomat dan proses pengolahan torakur beserta diversifikasi olahan tomat}

Sosialisasi diberikan dalam bentuk presentasi kepada Ibu-ibu Kelompok Tani tentang pentingnya manfaat tomat bagi kesehatan tubuh manusia. Hal ini dikarenakan buah tomat mengandung komponen nutrisi yang lengkap terutama kaya akan vitamin dan mineral. Vitamin dan mineral yang terdapat pada tomat adalah vitamin $\mathrm{A}$, vitamin $\mathrm{C}$, vitamin $\mathrm{B}$, zat besi kalsium. Komponen tersebut menjadikan tomat sebagai bahan pangan yang bergizi dan bersifat fungsional. Pemberian informasi ini dibutukhan agar peserta memiliki wawasan tentang manfaat tomat bagi tubuh.

Pelaksanaan kegiatan ini dapat diterima oleh mitra berdasarkan responden angket (kuesioner). Indikator keberhasilan sosialisasi ini ditandai peningkatan pengetahuan mitra dalam memahami akan materi yang diberikan dan diikuti banyaknya 
pertanyaan yang diajukan oleh peserta pelatihan yang terdiri dari mitra dan anggota kelompok mitra. Pengetahuan mitra bertambah mengenai pemanfaatan tomat yang bisa diolah menjadi beberapa produk seperti torakur, sari buah, permen jelly tomat, dan lain-lain yang sebelumnya tidak diketahui. Total peserta pelatihan sebanyak 25 orang, terlihat jawaban responden menyatakan menjadi tahu 25 orang (100\%) sedangkan tidak tahu sebanyak 0 orang.
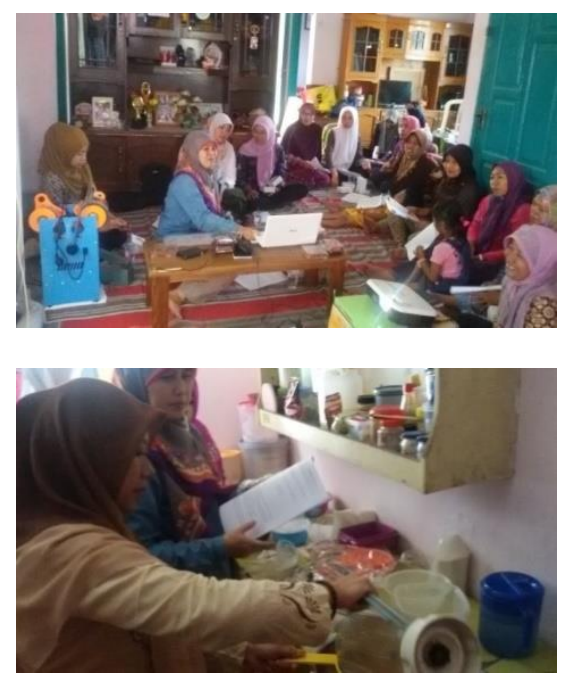

Gambar 1. Pelaksanaan penyuluhan dan pelatihan pengolahan torakur dan olahan tomat

\section{Pelatihan proses pengolahan torakur dan diversifikasi produk olahan tomat}

Keterampilan proses pengolahan dan diversifikasi produk olahan pangan adalah penting disampaikan untuk mengantisipasi anjloknya harga komoditas pada waktu panen raya atau dalam rangka memperluas pasar. Pengolahan tomat menjadi torakur dan diversifikasi olahan dapat meningkatkan nilai ekonomisnya, memperpanjang masa simpan dan memperluas pemasarannya. Pada pelatihan ini mitra diberi informasi melalui modul "Tomat dan Olahan Tomat" dan praktek secara langsung. Pelatihan ini dilakukan dengan langsung praktek pembuatan torakur, permen jelly dan selai tomat. Rasa produk torakur mendapatkan respon yang positif dari mitra terbukti sangat disukai, sebab tekstur dan rasanya yang mirip sekali seperti kurma. Permen jelly tomat dari hasil samping pembuatan torakur juga sangat disukai oleh peserta.

Hasil kuesioner pelatihan proses pengolahan tomat dan diversifikasi olahannya terhadap dari 20 orang diperoleh jawaban responden menyatakan bahwa 18 orang (90\%) menjadi terampil untuk membuat produk tersebut sendiri. Dari data tersebut terlihat bahwa mitra sangat menerima dengan pelatihan yang diberikan karena menambah pengetahuan dan ketrampilan peserta tentang pengolahan tomat yang sebelumnya tidak diketahui.

\section{Alih teknologi peralatan produksi tepat guna}

Alih teknologi peralatan produksi tepat guna sangat diperlukan dalam membantu kelancaran proses pengolahan. Pengolahan yang baik dapat meningkatkan kualitas hasil olahan. Pengolahan torakur pada prinsipnya menggunakan metode pengawetan dengan gula, perebusan, dan pengeringan. Alih teknologi menggunakan alat pengering yang sederhana tapi tepat guna diperlukan oleh masyarakat. Alat yang diberikan adalah alat pengering yang memanfaatkan energi sinar matahari atau bisa menggunakan kompor minyak / gas sebagai sumber panas. Alat pengering ini bisa digunakan untuk jangka waktu yang lama, karena menggunakan bahan galvalum sebagai bahan dasar sehingga mudah dibersihkan dan mudah dalam penyimpanan. Beberapa alih teknologi alat adalah vacuum sealer dan cup sealer, selain itu juga pemberian bantuan beberapa alat yang dibutuhkan yaitu panci, baskom, pisau dan lain sebagainya.

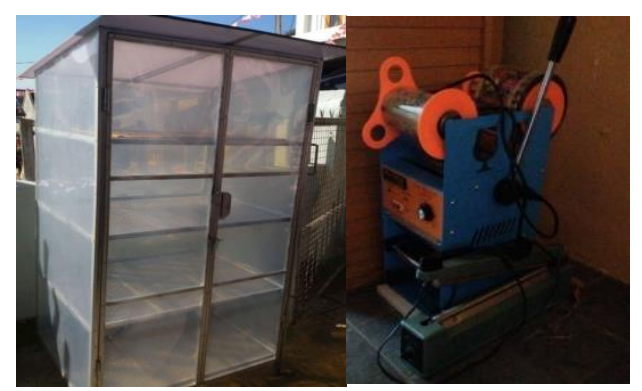

Gambar 2. Peralatan produksi tepat guna 
Berdasarkan hasil kuesioner, alih teknologi peralatan produksi tepat guna dapat diterima oleh mitra. Ketersediaan peralatan produksi yang tepat guna untuk pengolahan tomat memudahkan mitra dalam melakukan produksi. Hasil kuesioner menyatakan bahwa mitra sangat menerima sebanyak 20 orang (100\%).

\section{Penyuluhan keamanan pangan, sanitasi dan higienis produk}

Penyuluhan ini memberikan pengertian dan penjelasan pentingnya berproduksi secara aman, saniter dan higienis, artinya membuat produk yang bersih, sehat dan aman untuk dikonsumsi. Penjelasan dimulai dari pemilihan bahan baku, proses produksi, pengemasan, lingkungan yang menjadi tempat berproduksi serta karyawan yang bekerja. Hal ini perlu dipahami karena dapat meningkatkan kepercayaan konsumen terhadap produk yang dihasilkan.

Hasil pelatihan kemanan pangan sanitasi dan higienis produk, manajemen usaha dan pemasaran dapat diterima oleh mitra berdasarkan responden angket (kuesioner). Pelatihan ini sangat diterima oleh mitra, yang ditunjukkan dari hasil kuesioner penyuluhan keamanan pangan, sanitasi dan higienis produk. Dari 20 peserta diperoleh jawaban responden menyatakan bahwa 18 orang (90\%) mampu menerapkan proses yang bersih dan higienis. Hal ini menunjukkan adanya keberhasilan sosialisasi dengan peningkatan pengetahuan mitra dalam memahami akan materi dan diikuti banyaknya pertanyaan.

\section{Pelatihan manajemen usaha dan pemasaran}

Pelatihan manajemen usaha merupakan suatu sistem keseluruhan dari kegiatan usaha untuk merencanakan, menentukan harga, promosi dan mendistribusikan produk olahan tomat sehingga dapat menghasilkan produk yang berkualitas. Sedangkan pelatihan pemasaran dimaksudkan sebagai transfer ilmu dan pengetahuan untuk merintis daerah pemasaran produk dan penanganan permintaan konsumen

Salah satu bentuk pelatihan manajemen usaha produksi olahan tomat, yaitu cara menghitung analisis usaha. Perhitungan analisis usaha merupakan semua biaya yang terjadi selama proses produksi sampai pemasaran produk. Tujuan analisis biaya adalah dapat merencanakan, mengendalikan biaya produksi, mengambil keputusan strategis sehingga dapat menghitung besarnya laba atau keuntungan yang di dapat. Pada proses pelatihan tim IbM memberikan contoh perhitungan analisis biaya pada pembuatan beberapa produk yaitu produksi torakur, permen jely dan selai.

Hasil pelatihan dapat diterima oleh mitra berdasarkan angket (kuestioner) manajemen usaha dan pemasaran produk. Hasil kuestioner dari 20 orang, 18 orang (90\%) jawaban responden menyatakan dapat menerima materi tentang manajemen usaha dan pemasaran. Indikator keberhasilan ditandai pengetahuan mitra dalam memahami materi yang diberikan dan diikuti banyaknya pertanyaan yang diajukan oleh peserta pelatihan. Diharapkan mitra memiliki kemampuan dalam analisis usaha menghitung biaya produksi, pendapatan, keuntungan dari setiap produksi, serta strategi dalam hal pemasaran.

Untuk mengetahui tingkat ketercapainya program luaran setiap kegiatan dilakukan monitoring dengan membagikan kuisoner setiap selesai pelaksanaan kegiatan. Hasil kuisioner diisi oleh mitra setelah mengikuti setelah pelaksanaan program kegiatansosialisasi, praktek pengolahan tomat dan pemberian materi materi mengenai sanitasi dan higienis produk, manajemen usaha dan pemasaran disajikan pada Tabel 1. 
Tabel 1. Hasil kuisioner terhadap mitra setelah pelaksanaan program kegiatan

\begin{tabular}{|c|c|c|c|c|}
\hline No. & Program/Materi & Keterangan peserta & Peserta & $\begin{array}{c}\text { Presentase } \\
(\%)\end{array}$ \\
\hline 1. & $\begin{array}{l}\text { Penyuluhan tentang tomat } \\
\text { dan manfaatnya, dan } \\
\text { proses pengolahan torakur } \\
\text { dan olahan tomat }\end{array}$ & $\begin{array}{l}\text { Tahu } \\
\text { Tidak tahu }\end{array}$ & $\begin{array}{c}25 \\
0\end{array}$ & $\begin{array}{c}100 \% \\
0 \%\end{array}$ \\
\hline 2. & $\begin{array}{l}\text { Praktek pengolahan torakur } \\
\text { dan olahan tomat }\end{array}$ & $\begin{array}{l}\text { Terampil } \\
\text { Tidak terampil }\end{array}$ & $\begin{array}{c}18 \\
2\end{array}$ & $\begin{array}{l}90 \% \\
10 \%\end{array}$ \\
\hline 3. & $\begin{array}{l}\text { Alih teknologi peralatan } \\
\text { produksi tepat guna }\end{array}$ & $\begin{array}{l}\text { Menerima } \\
\text { Tidak menerima }\end{array}$ & $\begin{array}{c}20 \\
0\end{array}$ & $\begin{array}{c}100 \% \\
0 \%\end{array}$ \\
\hline 4. & $\begin{array}{l}\text { Pelatihan sanitasi dan } \\
\text { higienis manajemen usaha } \\
\text { dan pemasaran }\end{array}$ & $\begin{array}{l}\text { Mampu } \\
\text { Tidak mampu }\end{array}$ & $\begin{array}{c}18 \\
2\end{array}$ & $\begin{array}{l}90 \% \\
10 \%\end{array}$ \\
\hline 5 & $\begin{array}{l}\text { Ketertarikan mitra membuat } \\
\text { produk torakur dan } \\
\text { pemasarannya }\end{array}$ & $\begin{array}{l}\text { Minat } \\
\text { Tidak berminat }\end{array}$ & $\begin{array}{c}18 \\
2\end{array}$ & $\begin{array}{l}90 \% \\
10 \%\end{array}$ \\
\hline
\end{tabular}

\section{Luaran program pengabdian kepada Masyarakat}

Tabel 2. Luaran program pengabdian kepada Masyarakat

\begin{tabular}{|c|c|c|c|}
\hline \multirow[t]{2}{*}{ No } & \multirow[t]{2}{*}{ Kegiatan } & Indikator kerja & \multirow[t]{2}{*}{ Luaran } \\
\hline & & Target & \\
\hline 1 & $\begin{array}{l}\text { Penyuluhan tentang } \\
\text { tomat dan } \\
\text { manfaatnya, serta } \\
\text { proses pengolahan } \\
\text { torakur dan olahan } \\
\text { tomat }\end{array}$ & $\begin{array}{l}\text { 1. Peningkatan pengetahuan mitra } \\
\text { akan manfaat tomat dan kemampuan } \\
\text { mitra tentang pengolahan tomat } \\
\text { menjadi torakur dan olahan tomat }\end{array}$ & \\
\hline 2 & $\begin{array}{l}\text { Praktek pengolahan } \\
\text { torakur dan olahan } \\
\text { tomat ( sari buah dan } \\
\text { permen jelly) }\end{array}$ & $\begin{array}{l}\text { Peningkatan ketrampilan mitra dalam } \\
\text { mengolah tomat menjadi torakur dan } \\
\text { olahan tomat }\end{array}$ & Produk \\
\hline 3 & $\begin{array}{lr}\text { Alih } & \text { teknologi } \\
\text { peralatan } & \text { produksi } \\
\text { tepat guna } & \end{array}$ & $\begin{array}{l}\text { Menerima peralatan produksi yang } \\
\text { tepat guna untuk pengolahan tomat } \\
\text { bagi mitra }\end{array}$ & $\begin{array}{l}\text { Alat produksi } \\
\text { torakur, sari } \\
\text { buah dan } \\
\text { permen jelly }\end{array}$ \\
\hline 4 & $\begin{array}{l}\text { Pelatihan sanitasi dan } \\
\text { higienis, manajemen } \\
\text { usaha dan pemasaran }\end{array}$ & $\begin{array}{l}\text { Peningkatan kemampuan mitra } \\
\text { pentingnya proses yang bersih dan } \\
\text { higienis serta peningkatatan } \\
\text { kemampuan mitra dalam manajemen } \\
\text { usaha dan cara pemasaran. }\end{array}$ & \\
\hline 5 & $\begin{array}{l}\text { Program } \\
\text { pendampingan }\end{array}$ & $\begin{array}{l}\text { Ketertarikan mitra } \\
\text { membuat produk } \\
\text { olahan tomat dan } \\
\text { pemasarannya }\end{array}$ & $\begin{array}{l}\text { Produksi sari } \\
\text { buah tomat } \\
\text { dan torakur }\end{array}$ \\
\hline
\end{tabular}


Tabel diatas merupakan luaran yang dihasilkan dari kegiatan program pengabdian pada masyarakat untuk meningkatkan nilai ekonomis dari tomat (Tabel 2). Tabel tersebut menunjukkan bahwa pada setiap program terdapat perubahan tingkat pemahaman, pengetahuan, ketrampilan dan minat mitra terhadap pengabdian oleh Tim IbM

\section{KESIMPULAN DAN SARAN}

\section{Kesimpulan}

Berdasarkan hasil pelaksanaan program maka dapat disimpulkan hal-hal sebagai berikut :

1. Terdapat peningkatan kemampuan dan pengetahuan kedua Mitra yang berasal dari kelompok tani dan Kelompok PKK mengenai tomat, pengolahannya menjadi torakur dan olahan lainnya seperti permen jelly tomat dan sari buah tomat.

2. Peningkatan ketrampilan kedua mitra setelah pelatihan proses pengolahan torakur dan olahan tomat lainnya seperti permen jelly tomat, sari buah tomat, selai tomat.

3. Kedua mitra mampu memanfaatkan alat teknologi tepat guna yang diberikan oleh Tim

4. Peningkatan kemampuan mitra mengenai pentingnya proses yang bersih dan higienis, manajemen usaha dan pemasaran produk

5. Ketertarikan mitra membuat produk olahan tomat dan pemasarannya

\section{Saran}

1. Perlunya pendampingan yang berkelanjutan agar program dapat berjalan sesuai dengan rencana
2. Perlunya pendampingan pengurusan ijin usaha bagi mitra melalui proses tahapan yang diperlukan, agar meningkatkan kepercayaan konsumen terhadap produk yang dihasilkan.

\section{UCAPAN TERIMA KASIH}

Ucapan terima kasih disampaikan pada Direktorat Penelitian dan Pengabdian kepada Masyarakat, Direktorat Jenderal Pendidikan Tinggi, Kementerian Riset, Teknologi dan Pendidikan Tinggi atas pendanaan kegiatan melalui skim Iptek bagi Masyarakat (IbM) Tahun 2016

\section{DAFTAR PUSTAKA}

Arifulloh. 2013. Ekstraksi Likopen dari Buah Tomat (Lycopersicum esculentum Mill.) dengan Berbagai Komposisi Pelarut. Skripsi. Fakultas MIPA. Universitas Jember. Jember.

Bintang M. Y, Jenki P., Hens O. 2013. Konstruksi dan Kapasitas Alat Pengering Ikan Tenaga Surya Sistem Bongkar Pasang. Jurnal Media Teknologi Hasil Perikanan 1 (2).

Buntaran,Wawan, Okid Parama Astirin, Edwi Mahajoeno. 2010. Effect Of Various Sugar Solution Concentrations On Characteristics Of Dried Candy Tomato (Lycopersicum Esculentum). Bioscience 2(2) : 55-61

Desrosier NW. 1988. Teknologi Pengawetan Pangan. Diterjemahkan oleh $\mathrm{M}$. Muljohardjo. UI Press. Jakarta. 